\title{
The Role of Personal Values and Perceived Social Support in Developing Socially Responsible Consumer Behavior
}

\author{
Imran Ali $^{1} \&$ Saud Mandurah ${ }^{1}$ \\ ${ }^{1}$ Faculty of Economics \& Administration, King Abdulaziz University Jeddah, Saudi Arabia \\ Correspondence: Imran Ali, Faculty of Economics \& Administration, King Abdulaziz University Jeddah, Saudi \\ Arabia. E-mail: imranalinim@gmail.com
}

Received: July 24, 2016

doi:10.5539/ass.v12n10p180
Accepted: August 2, $2016 \quad$ Online Published: September 19, 2016

URL: http://dx.doi.org/10.5539/ass.v12n10p180

\begin{abstract}
Corporate social responsibility (CSR) is a longstanding theme in marketing research. Although plenty of research have been done to examine the influence of CSR activities on consumer behavior, less attention is paid to explore the psychological factors that shape consumer's socially responsible behavior (SRB). The current research addresses this gap by reviewing and comparing the literature from psychology and marketing streams that moves towards a degree of convergence. It examines the psychological role of personal values and external factors like perceived social support to build pro-social behavior among consumers. The personal values include; self-transcendence and self-enhancement values and perceived social support by social network in shaping consumer's socially responsible behavior. The study proposed and tested the theoretical model using Structural Equation Model (SEM) technique. Data is collected through self-administered survey from 450 consumers in Pakistan. The study found that higher self-transcendence values leads to higher level of socially responsible behavior among consumers. Whereas self-enhancement values has negative influence on consumers in adopting socially responsible behavior. The social networks including; parents, friends/peers, teachers' play important role in development of socially responsible behavior among consumers as individuals tend to pay focus on the recommendations of their members in their social networks. The findings of this study provide important recommendations to the corporate policy makers to ensure sustainable organizational performance in today's competitive business environment.
\end{abstract}

Keywords: personal values, self-transcendence and self-enhancement, social support, socially responsible consumer behavior

\section{Introduction}

Organizational concerns about social wellbeing has increased strikingly in recent years and companies are striving to minimize their hurtful actions and maximize their impact for societal welfare (Crilly et al., 2008). Numbers of scholars have examined the impact of corporate social responsibilities (CSR) activities on multiple stakeholders including investors, employee and consumers. Literature provide ample evidence on the role of CSR activities in developing socially responsible behavior among consumers. The awareness of CSR has not only fascinated corporations but also individual stakeholders which resulted in adoption of socially responsible investment principles among investors (socially responsible investors) socially responsible consumers (green consumers) and pro-social behavior among employees (Sen et al., 2006). Although plenty of research have been conducted to examine the influence of CSR activities in developing socially responsible behavior among consumer through green purchase intentions. There is limited amount of research available in business literature that identify the psychological factors that play important role in shaping socially responsible behavior among consumers.

There is call for research to investigate the personal characteristics that hearten individuals to seek for social welfare rather than wealth maximization (Crilly et al., 2008), which support (Wood, 1991) call to articulate 'a principle of socially responsible human action'. The present study fills this gap by investigating the role of Schwartz's (1992) theory of personal values including self-transcendence and self-enhancement in shaping socially responsible behavior among consumers. It also examines the influence of support received from one's social network in adoption of socially responsible consumption behavior. The role of social support network in shaping individual's behavior is very interesting and used in different studies in various perspectives. However, 
less work has been done so far to investigate the association between social support network in developing socially responsible behavior among consumers. In this way, the study integrates two research streams; psychology and marketing to propose conceptual model to be tested through Structural Equation Model (SEM).

The contribution of this study includes integration of psychological factors (personal values and support from social network) and marketing variables (socially responsible consumer behavior). This research will answer two important research question; (i) how do personal values (self-transcendence and self-enhancement) influence consumer's socially responsible behavior? and (ii) and how does perceived support from social network affect consumer's socially responsible consumption behavior?

\subsection{Personal Values}

Values are the believes that people perceive as desirable, and that guide individuals' attitude and behaviors (Allport et al., 1951; Crilly et al., 2008; Higgins, 2006; Rokeach, 1973). Individual's decision are driven by their interests and personal values (Hemingway \& Maclagan, 2004). The theory of human value was presented by Schwartz and Bilsky (1990). Schwartz (1992) identified 10 dimensions of personal values namely: universalism, benevolence, conformity, tradition, security, power, achievement, hedonism, stimulation, and self-direction.

Universalism and benevolence are related to self-transcendence, self-enhancement values includes: power, achievement and hedonism. Whereas openness to change are characterized by self-direction, and stimulation values, and conservation includes conformity, tradition and security values. Research suggests that people with different set of values practice specific kind of behavior. We can therefore, predict behavior of people by identifying the type of values they practice in their personality. Figure 1 presents different sets of values and their corresponding behaviors as proposed by Schwartz (1992).

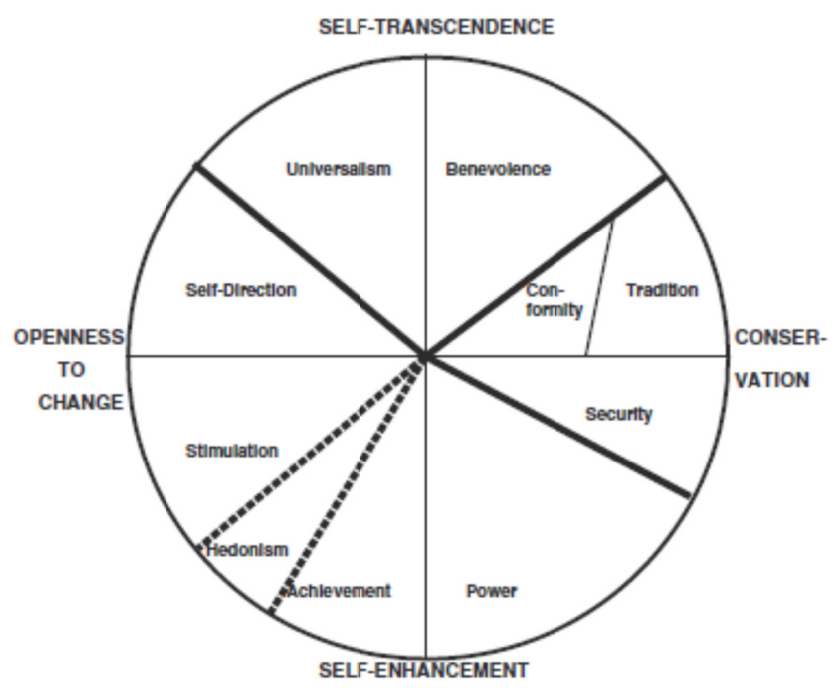

Figure 1. Schwartz's (1992) model of personal values

\subsection{Socially Responsible Consumer Behavior}

CSR has been fascinating research scholars from across disciplines including management, marketing, human resources management, finance and organizational behavior over last 20 years (Sen \& Bhattacharya, 2001). Despite extensive research on CSR, there has been debate on the definition of CSR since 1950's (Carroll, 1990; Wood, 2010). CSR is attributed as an 'organizational' activity, for instance Davis (1973:312) believe CSR as "the firm's consideration of, and response to, issues beyond the narrow economic, technical, and legal requirements of the firm." Number of researchers believe CSR as an antecedent to improve organizational performance (Wood, 1991) and to respond to societal pressures (Bansal \& Roth, 2000). CSR is considered as internally complex, however relatively flexible in application (Galbreath \& Shum, 2012; Wood, 2010). The general perceptions about CSR is that the companies should respond to social wellbeing being beyond profit maximization (Galbreath \& Shum, 2012; Matten \& Moon, 2008). Carroll (1979) believe CSR as "economic, legal, ethical, and discretionary expectations that society has of organizations at a given point in time". Companies are rapidly adopting CSR practices including: donations to charitable institution, community welfare 
programs, helping communities in natural disasters, reduction in environmental hazards (Albinger \& Freeman, 2000). CSR activities are helpful meeting stakeholders' dynamic and increasing expectations towards organizations (Hansen, Dunford, Boss, Boss, \& Angermeier, 2011; Matten \& Moon, 2008; Su, Huang, van der Veen, \& Chen, 2014).

Sen and Bhattacharya (2001) indicate the importance of CSR for different stakeholders including customers, employees and investors and found that CSR plays important role in shaping favorable behaviors among these stakeholders. This study examines the influence of CSR in consumers' perspective. Consumer being a key stakeholder has gain much attention in CSR research as scholar investigated the influence of CSR on consumer behavior in numerous studies. For example Ellen, Mohr, and Webb (2000) examined influence of cause-related marketing on consumers' reaction regarding purchase decision. Sen and Bhattacharya (2001) also studied the congruence between consumers' perception of CSR, their characteristics and their reactions to CSR initiatives. The current study also examines how does consumers personal values and perceived support from ones social network determine their socially responsible consumption behavior.

\subsection{Hypotheses Development}

\subsubsection{Personal Values and Socially Responsible Behavior}

Schwartz (1992) value theory has been used and applied widely in social sciences (Meglino and Ravlin, 1998). Bardi and Schwartz (2003) proposed that "the natural way to pursue important values is to behave in ways that express them or promote their attainment". Similarly, Roccas and Sagiv (2009) hold that "one of the reasons for the interest in understanding personal values is their effects on behavior, and that 'personal values have been found to be associated with a large variety of behaviors". Researchers have analyzed the influence of personal values in shaping social and economic behaviors. For instance, Crilly et al. (2008) found association between personal values and moral reasoning that leads to pro-social behavior among individuals. Similarly, Lonnqvist, Verkasalo, Wichardt, and Walkowitz (2013) examined the association between personal values and pro-social behaviors. Lonnqvist et al. (2013) also found that personal values may predict pro-social behavior, however the strength of association between the two depends upon the individual differences amongst people.

The current study considers two types of personal values including self-transcendence and self-enhancement. Self- transcendence includes the values that "motivate people to transcend selfish concerns and promote the welfare of others, close and distant, and of nature" (Schwartz, 1992). It includes universalistic and benevolent values. Universalism refers to values that encourages appreciation and tolerance towards people and nature and promotion of equity, justice and caring nature. These values endorse feelings of welfare of others and protecting others interests among individuals. Benevolence refers to set of values "preserving and enhancing the welfare of those with whom one is in frequent personal contact" (Schwartz, 1992). Crilly et al., (2008); Egri and Herman (2000); and Whitener, Susan, Brodt, Audrey, and Jon (1998) noted that people who have concern for others (self-transcendence) have more pro-social behavior. Sagiv, Sverdlik, and Schwarz, (2011) argued that self-transcendence values promotes pro-social behavior. Lonnqvist et al. (2013) also noted positive association among self-transcendence values and pro-social behavior.

Self-enhancement values includes: power, achievement and hedonism. People that value achievement and gaining more power are likely to compete for social recognition and self-esteem which limit their ability to act in the interest of others and display self-centered attitudes (Schwartz \& Bilsky, 1990). As opposed to self-transcendence values, self-enhancement encourage personal and self interest even at the cost of others and not thinking for the welfare of others (Crilly et al., 2008; Schwartz, 1992). Hedonism is also one the prominent value of self-enhancement, people who practice this value tend to satisfy their own desires having lack of self-sacrifice, they refrain to assist others and engage in promotion of their self-interest (Holmes et al., 2002). Based on these theoretical arguments, the current study proposed below hypotheses.

H1: Higher level of self-transcendence values leads to higher level of socially responsible behavior among consumers.

H2: Higher level of self-enhancement values leads to lower level of socially responsible behavior among consumers.

\subsubsection{Social Support and Socially Responsible Behavior}

Social support from the one's network also influence in developing socially responsible behavior among consumers. The role of social capital is very important in this regard, social capital refers to the resources available to people through their social networks (Linbn, 2001). Social networks promotes social values among people to adopt socially responsible behavior (Brady, Schlozman, \& Verba, 1999). Bekker (2006) also holds that 
"Networks facilitate pro-social behavior because they enforce social norms that prescribe such behavior, and individuals want to avoid disapproval for a failure to give". Valor et al. (2012) hold that responsible consumption behavior is shaped in different time spans of one's life starting from childhood, and individual's environment and social network influence in developing his/her responsible consumption behavior. In another important study, Valor and Carrero (2014) argue social consumption as social activity and consumer believe responsible consumption and personal project effected by the beliefs and norms of others' projects in their interpersonal network. On the basis of these theoretical arguments, this study propose pro-social consumption is influenced by the support people receive from their social network.

H3: Higher level of social support leads to more socially responsible behavior among consumers.

\subsection{The Conceptual Model}

The conceptual model of this study is presented in Figure 2, the independent variables are personal values and social support from one's social network. The personal values includes self-transcendence and self-enhancement. The dependent variable in this research is socially responsible consumer behavior.

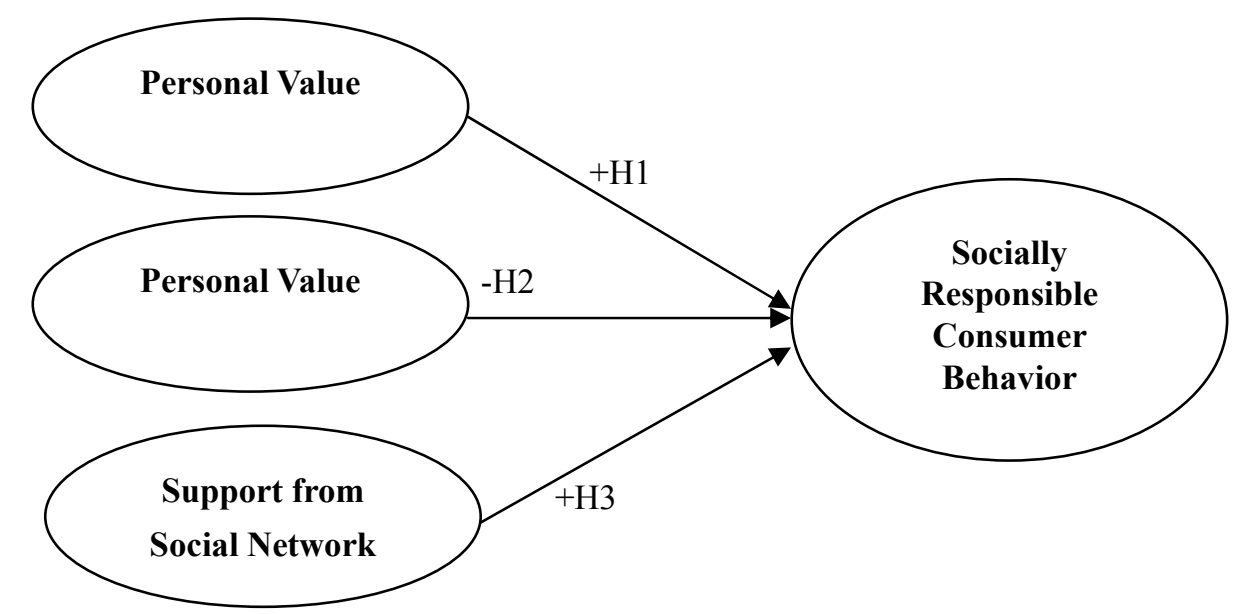

Figure 2. Conceptual Model

\section{Materials and Methods}

\subsection{Sample and Data Collection}

The unit of analysis in current research are individual consumers. We believe that university students being rational consumers experience consumption experiences and choose products from multiple options. The data has been collected from business students including post graduate professional students working in various industries of Pakistan. The data has been collected from 450 students having diverse socio-economic background through self-administered survey questionnaire in classrooms. The sample students included males and females, from different urban/rural areas, different cities of Pakistan.

\subsection{Instruments and Measures}

The instrument to measure personal values (self-transcendence and self enhancement) has been adopted from the Schwartz Value Survey (Schwartz, 1992). Self-transcendence has three dimensions: power, achievement and hedonism, and self-enhancement has two dimensions including universalism and benevolent values. The sample items includes: "it's very important for me to help the people around me, I want to care for other people. I think it is important that every person in the world be treated equally. I want justice for everybody, even for people I don't know". The instrument to measure value items is 1 for strongly disagree and 5 for strongly agree. The instrument to measure pro-social behavior has been adopted from Webb et al., (2008). The respondents were asked to think about the behaviors of corporations regarding (1) "how companies behave toward their employees, the community, and the environment" and (2) "the environmental impact of the products themselves, before their purchase decision". The respondents were given 4 options and they had to choose one option out of given options. The option that describe their socially responsible consumption behavior is 'I make an effort to learn about these issues, and I am willing to pay more or sacrifice product quality in order to use these issues in my purchase decisions'. 
The instrument to measure social support from network (including parents, peers and teachers) has been adopted from the work of Malecki and Demaray, (2002); Fraser et al., (1996); Johnson et al., (1983); and Ahmed et al. (2010), which examines the influence of social network in promotion of learning behavior among adolescents. The instrument contains 4 items: "my parents always advise and inspires me to adopt socially responsible consumption behavior, I always get motivation from my friends and peers to practice socially responsible consumption behavior. My teachers always encourage me to consume socially responsible products. Overall, I feel good support from my social network to practice socially responsible consumption behavior". The instrument is measure through 5 point Likert scale where 1 is for strongly disagree and 5 for strongly agree.

\subsection{Procedure}

The data is collected through self-administered survey is entered into SPSS sheet for further analysis. SPSS and AMOS software are used to analyze data. The analysis techniques includes descriptive analysis, reliability analysis using Cronbach Alpha and correlation analysis through SPSS software. Confirmatory Factor Analysis (CFA) is performed to examine the validity of the measurement instruments, whereas Structural Equation Modeling (SEM) technique is used to test the proposed hypotheses and verify the suggested conceptual model.

\section{Results}

\subsection{Reliability and Validity Analysis}

The construct reliability has been computed through composite reliability and Cronbach aplha. The values of composite reliability are $0.95,0.90,0.91$, and 0.96 , whereas the values of Cronbach aplha are $0.91,0.89,0.90$, and 0.94 for personal values, support from social network and socially responsible consumer behavior constructs, respectively. The standard criteria for reliability is that the values of Cronbach alpha should be higher than 0.70 (Nunnaly, 1978). The values for composite reliability and Cronbach aplha of all variables in this study meets above parameter, we therefore confirm the reliability of data and its fitness to be used for further analysis. The validity of the measurement instruments is also tested using Confirmatory Factor Analysis (CFA) technique using AMOS software. CFA is used to measure if the constructs are consistent with the researcher's understanding of the factor. The standard criteria for validity of measurement scale in CFA is that the value of factor loading should be more than 0.40 . The items scoring less than 0.40 should be removed from the scale due to their inconsistency with the measurement construct as perceived by the respondents. It is also very important the examine the values of Model Fit for CFA. According to Gerbing and Anderson (1992); and Hair et al. (2003) the values of model fit ratios including CFI, GFI, and NFI should be closer to 0.90 and the value of RMSEA should be between 0 to 1 . The values of CFI, GFI and NFI are 1.23, 0.94 and 0.98 respectively, which is well above 0.90 , we therefore assume model fitness for our CFA. The value of RMSEA (0.03) is also well below than 1 confirming fitness of our measurement model in this study. A good model fit that proposed research model is plausible (Schermelleh-Engel et al., 2003). The results of reliability and validity analysis are provided in Table 1 below. The values for average variance extracted (AVE) also satisfies the minimum benchmark of 0.50 as presented in Table 1 below.

\subsection{Correlation Analysis}

The Pearson correlation has been computed in this study. The Pearson correlation is a measure of the linear correlation between different variables, where 1 is total correlation, 0 no correlation and -1 negative correlation between the variables (Pearson, 1895). The values of correlation are shown in Table 2. All values are well above 0 , depicting the linear correlation between the variables under investigation in this study. Self-enhancement is having negative relationships with social support, and socially responsible behaviors among consumers. The values of mean and standard deviation are also normal and meeting the standard criteria as depicted in Table 2. There is no multi-coleaniarity issue amongst the variables in this study.

Table 1 . Reliability and validity analysis

\begin{tabular}{|c|c|c|c|c|c|}
\hline Variables & Item Coding & Factor Loading & Composite reliability & Cronbach Alpha $(\alpha)$ & AVE \\
\hline \multicolumn{2}{|c|}{ Self-transcendence } & & 0.95 & 0.91 & 0.58 \\
\hline \multirow{3}{*}{ Benevolence } & Ben1 & 0.61 & & & \\
\hline & Ben2 & 0.74 & & & \\
\hline & Ben3 & 0.88 & & & \\
\hline \multirow{2}{*}{ Universalism } & Uni1 & 0.60 & & & \\
\hline & Uni2 & 1.02 & & & \\
\hline
\end{tabular}




\begin{tabular}{|c|c|c|c|c|c|}
\hline & Uni3 & 0.76 & & & \\
\hline & Uni4 & 0.63 & & & \\
\hline & Uni5 & 0.84 & & & \\
\hline & Uni6 & 0.65 & & & \\
\hline Self-enhance & & & 0.90 & 0.89 & 0.66 \\
\hline & Hed1 & 0.78 & & & \\
\hline & Hed2 & 0.68 & & & \\
\hline Hedonism & Hed3 & 0.66 & & & \\
\hline & Hed4 & 0.57 & & & \\
\hline & Hed5 & 0.54 & & & \\
\hline & Ach1 & 0.83 & & & \\
\hline Achievement & Ach2 & 0.92 & & & \\
\hline ACIICV VEIIII & Ach3 & 1.17 & & & \\
\hline & Ach4 & 0.82 & & & \\
\hline & Pow1 & 0.93 & & & \\
\hline Power & Pow2 & 0.85 & & & \\
\hline & Pow3 & 0.78 & & & \\
\hline & SSup1 & 0.82 & & & \\
\hline Social Support from & SSup2 & 0.68 & 091 & 090 & 050 \\
\hline Network & SSup3 & 0.69 & & & 0.50 \\
\hline & SSup4 & 0.54 & & & \\
\hline & SRCB1 & 0.74 & & & \\
\hline Socially responsible & SRCB2 & 0.66 & 096 & 0.94 & 0.54 \\
\hline consumer behavior & SRCB3 & 0.84 & 0.30 & & \\
\hline & SRCB4 & 0.68 & & & \\
\hline
\end{tabular}

Note: $\mathrm{CFI}=0.93 ; \mathrm{GFI}=0.94 ; \mathrm{NFI}=0.98 ; \mathrm{AGFI}=0.92 ; \mathrm{NNFI}=0.87 ; \mathrm{RMSEA}=0.03 ; \mathrm{RMR}=0.037$.

Table 2. Correlation matrix

\begin{tabular}{ccccc}
\hline & S. Trans. & S. Enh. & S.S & PSB \\
\hline Self-transcendence & - & & & \\
Self-enhancement & 0.70 & - & & \\
Social Support (S.S) & $0.61^{* *}$ & -0.47 & - & - \\
Pro-social Behavior (PSB) & $0.44^{*}$ & $-0.32^{*}$ & $0.50^{* *}$ & 3.38 \\
Mean & 3.62 & 3.48 & 3.94 \\
S.D & 0.73 & 0.50 & 0.58 & 1.07 \\
\hline
\end{tabular}

* Significant at 0.01 level

** Significant at 0.05 level

\subsection{Hypotheses Testing using SEM}

Hypotheses proposed in study have been tested empirically using SEM technique. The model fit indices are also good for SEM assumptions. As mentioned above, according to Gerbing and Anderson (1992); and Hair et al. (2003) the values of model fit ratios including CFI, GFI, and NFI should be closer to 0.90 and the value of RMSEA should be between 0 to 1 . The scores of CFI, GFI and NFI are $0.93,0.85$ and 0.95 respectively, which is well above 0.90, we therefore assume model fitness for our CFA. The value of RMSEA (0.05) is within the threshold confirming fitness of our measurement model in this study (Bollen, 1989). A good model fit does not necessarily means that model is correct, however it indicates that the proposed research model is plausible (Schermelleh-Engel et al., 2003).

The results of regression analysis in SEM as presented in Table 3 shows a positive and highly significant (beta $=$ 
0.48 and P-value $=0.01)$ relationship between self-transcendence and socially responsible behavior among consumers leaving our $\mathrm{H} 1$ accepted. Our $\mathrm{H} 2$ is propose negative relationship between self-enhancement and socially responsible behavior among consumers. The value of beta is -0.19 which shows negative association between the two variables, the relationship is also significant at $5 \%$ level we therefore, accept our hypothesis. The study also noted a highly significant $(\mathrm{P}$-value $=0.00)$ and positive (beta value $=0.67$ ) association between social support and socially responsible behavior among consumers, we therefore accept our $\mathrm{H} 3$ as well.

Table 3. Structural equation model

\begin{tabular}{|c|c|c|c|c|c|}
\hline Hypothesis & SEM Path & Beta & t-value & Significance & Decision \\
\hline $\mathrm{H} 1$ & $\begin{array}{c}\text { Self-transcendence - Socially Responsible } \\
\text { Behavior }\end{array}$ & 0.48 & 2.58 & 0.01 & Supported \\
\hline $\mathrm{H} 2$ & Self-enhancement - Responsible Behavior & -0.19 & 2.06 & 0.04 & Supported \\
\hline $\mathrm{H} 3$ & $\begin{array}{l}\text { Social Support -Socially Responsible Behavior } \\
\text { (SRB) }\end{array}$ & 0.67 & 3.31 & 0.00 & Supported \\
\hline
\end{tabular}

Note: $\mathrm{CFI}=0.93 ; \mathrm{GFI}=0.95 ; \mathrm{NFI}=0.95 ; \mathrm{AGFI}=0.98 ; \mathrm{NNFI}=0.92 ; \mathrm{RMSEA}=0.05 ; \mathrm{RMR}=0.02$.

\section{Discussion}

\subsection{Self-transcendence and Socially Responsible Behavior}

The study found significant positive association between self-transcendence and socially responsible behavior among consumers. This findings is consistent with the outcomes of many previous studies, literature provides ample evidence on the positive association between self-transcendence and socially responsible behavior among consumers. For instance, Crilly et al., (2008); Egri and Herman (2000); Lonnqvist et al., (2013); Sagiv et al., (2011) and Whitener, et al., (1998) argued that self-transcendence values promotes pro-social behavior. Consumers who have concern for others (self-transcendence) are likely to exhibit pro-social behavior.

\subsection{Self-enhancement and Responsible Behavior}

Self-enhancement promotes self-interest among consumers. The study found negative association between self-enhancement and socially responsible behavior among selected consumers. This findings is also in line with previous studies. Many previous studies including (Crilly et al., 2008; Holmes et al., 2002) noted that people who practice self-enhancement tend to satisfy their own desires and lack of self-sacrifice, therefore practice less pro-social consumption behavior.

\subsection{Social Support and Socially Responsible Behavior}

Our last accepted hypothesis is related to positive association between social support and socially responsible consumption behavior. Many studies including: Brady et al. (1999; Bekker (2006); and Linbn (2001) hold that social networks promotes social values among members to adopt socially responsible consumption behavior.

\section{Conclusion}

The present study proposed a conceptual model that examines the influence of psychological variables (personal values) and social factors (perceived social support to adopt socially responsible behavior) in development of socially responsible behavior among consumers. The theoretical model has been proposed on the basis of arguments developed after extensive literature review, the theoretical model is also empirically tested to validate the arguments presented in this study. The study concludes that higher self-transcendence values leads to higher level of socially responsible behavior among consumers. Whereas self-enhancement values has negative influence on consumers in adopting socially responsible behavior. The social networks including: parents, friends/peers, teachers also plays important role in development of socially responsible behavior among consumers as individuals tend to pay focus on the recommendations of their members in their social networks. The findings of this study has implications for diverse stakeholders including marketing managers, corporate social responsibility managers/officers. The study suggests that self-transcendence values including benevolence and universalism should be encouraged among people to promote their pro-social behavior. People should not always think about themselves only, but for the betterment of others in order to promote wellbeing among society. Secondly, we should not only focus on individuals but also their social networks if we want to promote socially responsible behavior among individuals. Consumers tend to get recommendations and inspirations from 
their social networks to practice socially responsible consumption behaviors, so it is important to advocate pro-social behavior in social networks.

The study suggests that some other psychological variables should also be explored to predict consumer's socially responsible behavior. Current study collected data from students, future study can focus on household consumers to finds more insights and practical perspectives. A larger sample size can of-course provide more authentic findings that could be generalized to larger population. Finally, a cross-cultural study in different cultures including individualistic versus collectivistic cultures can also provide more meaningful findings related to the role of social networks in developing consumer behavior. Greet Hofstede's theory of national culture can us useful for differentiating different countries on the basis of their cultural typologies. As Pakistani culture is more collectivistic than individualistic people consult recommendations from their social networks, this could be different in some other country having individualistic culture.

\section{References}

Ahmed, W., Minnaert, A., ven der Werf, G., \& Kuyper, H. (2010). Perceived social support and early adolescents' achievements: The meditational roles of motivational believes and emotions. Journal of Youth Adolescents, 39, 36-46. http://dx.doi.org/10.1007/s10964-008-9367-7

Albinger, H. S., \& Freeman, S. J. (2000). Corporate social performance and attractiveness as an employer to different job seeking populations. Journal of Business Ethics, 28, 243-253. http://dx.doi.org/10.1023/A: 1006289817941

Allport, G. W., Vernon, P. E., \& Lindzey, G. (1951). Study of values. Cambridge: The Riverside Press.

Bansal, P., \& Roth, K. (2000). Why companies go green: A model of ecological responsiveness. The Academy of Management Journal, 43(4), 717-736. http://dx.doi.org/10.2307/1556363

Bardi, A., \& Schwartz, S. H. (2003). Values and behavior: Strength and structure of relations. Personality and Social Psychology Bulletin, 29, 1207-1220. http://dx.doi.org/10.1177/0146167203254602

Bekkers, R. (2006). Traditional and health-related philanthropy: The role of resources and personality. Social Psychology Quarterly, 69(4), 349-366. http://dx.doi.org/10.1177/019027250606900404

Bollen, K. A. (1989). Structural equations with latent variables. New York: John Wiley \& Sons. http://dx.doi.org/10.1002/9781118619179

Brady, H. E., Schlozman, K. L., \& Verba, S. (1999). Prospecting for Participants: Rational Expectations and the Recruitment of Political Activists. The American Political Science Review, 93(1), 153-168. http://dx.doi.org/10.2307/2585767

Carroll, A. B. (1979). A three-dimensional conceptual model of corporate social performance. Academy of Management Review, 4, 497-505.

Carroll, A. B. (1999). Corporate social responsibility: Evolution of a definitional construct. Business and Society, 38, 268-295. http://dx.doi.org/10.1177/000765039903800303

Crilly, D., Schneider, S. C., \& Zollo, M. (2008). Psychological antecedents to socially responsible behavior. European Management Review, 5, 175-190. http://dx.doi.org/10.1057/emr.2008.15

Davis, K. (1973). The case for and against business assumption of social responsibilities. Academy of Management Journal, 16, 312-323. http://dx.doi.org/10.2307/255331

Egri, C. P., \& Herman, S. (2000). Leadership in the North American environmental sector: Values, leadership styles, and contexts of environmental leaders and their organizations. Academy of Management Journal, 43, 571-604. http://dx.doi.org/10.2307/1556356

Ellen, P. S., Mohr, L. A., \& Webb, D. J. (2000). Charitable Programs and the Retailer: Do they Mix?. Journal of Retailing, 76(3), 393-406. http://dx.doi.org/10.1016/S0022-4359(00)00032-4

Fraser, B. J., McRobbie, C. J., \& Fisher, D. L. (1996). Development, validation and use of personal and class forms of a new classroom environment instrument. Paper presented at the annual meeting of the American Educational Research Association, New York.

Galbreath, J., \& Shum, P. (2012). Do customer satisfaction and reputation mediate the CSR-FP link? Evidence from Australia. Australian Journal of Management, 37, 211-229. http://dx.doi.org/10.1177/031289621 1432941

Gerbing, D. W., \& Anderson, J. C. (1992). Monte Carlo evaluations of goodness of fit indices for structural 
equation models. Sociological Methods \& Research, 21(2), 132. http://dx.doi.org/10.1177/00491241920 21002002

Hair, J. F., Babin, B., Money, A. H., \& Samouel, P. (2003). Essentials of business research methods. John Wiley \& Sons, Inc.

Hansen, S. D., Dunford, B. B., Boss, A. D., Boss, R. W., \& Angermeier, I. (2011). Corporate social responsibility and the benefits of employee trust: A cross-disciplinary perspective. Journal of Business Ethics, 102(1), 29-45. http://dx.doi.org/10.1007/s10551-011-0903-0

Hemingway, C. A., \& Maclagan, P. W. (2004). Managers' personal values as drivers of corporate social responsibility. Journal of Business Ethics, 50, 33-44. http://dx.doi.org/10.1023/B:BUSI.0000020964.80208. c9

Higgins, E. T. (2006). Value from hedonic experience and engagement. Psychological Review, 113(3), 439-460. http://dx.doi.org/10.1037/0033-295X.113.3.439

Holmes, J. G., Miller, D. T., \& Lerner, M. J. (2002). Committing altruism under the cloak of self-interest: the exchange fiction. Journal of Experimental Social Psychology, 38, 144-151. http://dx.doi.org/10.1006/jesp. 2001.1494

Johnson, D. W., Johnson, R., \& Anderson, D. (1983). Social interdependence and classroom climate. The Journal of Psychology, 114, 135-142. http://dx.doi.org/10.1080/00223980.1983.9915406

Lin, N. (2001). Social capital: social networks, civic engagement or trust? Hong Kong Journal of Sociology, (2), $1-38$.

Lonnqvist, J., Verkasalo, M., Wichardt, P. C., \& Walkowitz, G. (2013). Personal values and prosocial behaviour in strategic interactions: Distinguishing value-expressive from value-ambivalent behaviours. European Journal of Social Psychology, 43, 554-569. http://dx.doi.org/10.1002/ejsp.1976

Malecki, C. K., \& Demaray, M. K. (2002). Measuring perceived social support: Development of the child and adolescent social support scale (CASSS). Psychology in the Schools, 39, 1-18. http://dx.doi.org/10.1002/ pits. 10004

Matten, D., \& Moon, J. (2008). "Implicit" and "explicit" CSR: A conceptual framework for a comparative understanding of corporate social responsibility. Academy of Management Review, 33, 404-424. http://dx.doi.org/10.5465/AMR.2008.31193458

Meglino, B. M., \& Ravlin, E. C. (1998). Individual values in organizations: Concepts, controversies, and research. Journal of Management, 24, 351-389. http://dx.doi.org/10.1177/014920639802400304

Nunnally, J. C. (1978). Assessment of Reliability. In Psychometric Theory (2nd ed.). New York: McGraw-Hill.

Pearson, K. (1895). Notes on regression and inheritance in the case of two parents. Proceedings of the Royal Society of London, 58, 240-242. http://dx.doi.org/10.1098/rspl.1895.0041

Roccas, S., \& Sagiv, L. (2009). Personal values and behavior: Taking the cultural context into account. Social and Personality Psychology Compass, 4, 30-41. http://dx.doi.org/10.1111/j.1751-9004.2009.00234.x

Rokeach, M. (1973). The nature of human values. New York: Free Press.

Schermelleh-Engel, K., Moosbrugger, H., \& Muller, H. (2003). Evaluating the fit of structural equation models: Tests of significance and descriptive goodness-of-fit measures. Methods of Psychological Research Online, $8(2), 23-74$

Schwartz, S. H. (1992). Universals in the content and structure of values. Theory and empirical tests in 20 countries. In M. Zanna (Ed.), Advances in experimental social psychology (Vol. 25, pp. 1-65). New York: Academic Press.

Schwartz, S. H. (1994). Are there universal aspects in the structure and contents of human values? Journal of Social Issues, 50, 19-45. http://dx.doi.org/10.1111/j.1540-4560.1994.tb01196.x

Schwartz, S. H., \& Bilsky, W. (1990). Towards a theory of the universal content and structure of values: Extensions and cross-cultural replications. Journal of Personality and Social Psychology, 58, 878-891. http://dx.doi.org/10.1037/0022-3514.58.5.878

Sen, S., \& Bhattacharya, C. B. (2001). Does doing good always lead to doing better? Consumer reactions to corporate social responsibility. Journal of Marketing Research, 38, 225-243. http://dx.doi.org/10.1509/jmkr. 38.2.225.18838 
Sen, S., Bhattacharya, C. B., \& Korschun, D. (2006). The role of corporate social responsibility in strengthening multiple stakeholder relationships: A field experiment. Journal of the Academy of Marketing Science, 34, 158-166. http://dx.doi.org/10.1177/0092070305284978

Su, L., Huang, S., van der Veen, R., \& Chen, X. (2014). Corporate social responsibility, corporate reputation, customer emotions and behavioral intentions: A structural equation modeling analysis. Journal of China Tourism Research, 10(4), 511-529. http://dx.doi.org/10.1080/19388160.2014.958606

Valor, C., \& Carrero, I. (2014). Viewing responsible consumption as personal project. Psychology and Marketing, 31(12), 1110-1121. http://dx.doi.org/10.1002/mar.20758

Valor, C., Merino, A., Carrero, I., Díaz, E., Labajo, V., \& Bilbao, P. (2012). Why One Becomes a Responsible Consumer: The Creation and Maintenance of Responsible Consumption as a Self-Determined Personal Project. Human Ecology Review, 19(2), 159-174.

Webb, D. J., Mohr, L. A., \& Harris, K. E. (2008). A re-examination of socially responsible consumption and its measurement. Journal of Business Research, 61(2), 91-98. http://dx.doi.org/10.1016/j.jbusres.2007.05.007

Whitener, E. M., Susan, E., Brodt, M., Audrey, K., \& Jon, M. W. (1998). Managers as initiators of trust: An exchange relationship framework for understanding managerial trustworthy behavior. Academy of Management Review, 23, 513-530.

Wood, D. J. (1991). Corporate social performance revisited. Academy of Management Review, 16, 691-718.

Wood, D. J. (2010). Measuring corporate social performance: A review. International Journal of Management Review, 12, 50-84. http://dx.doi.org/10.1111/j.1468-2370.2009.00274.x

\section{Copyrights}

Copyright for this article is retained by the author(s), with first publication rights granted to the journal.

This is an open-access article distributed under the terms and conditions of the Creative Commons Attribution license (http://creativecommons.org/licenses/by/4.0/). 